\title{
Observations “Detections” of Shallow Unconventional Qusaiba Shale Gas Reservoirs North Part of Saudi Arabia
}

\author{
Mamdoh Alajmi' ${ }^{1}$, Abdulrahman Alotaibi ${ }^{1}$, Essam Aboud ${ }^{2}$, Aqeel Alharbi ${ }^{1}$, Majed Almalki ${ }^{1}$ \\ ${ }^{1}$ King Abdulaziz City for Science and Technology, National Center of Oil and Gas, Riyadh, KSA \\ ${ }^{2}$ King Abdulaziz University, Natural Hazard Center, Jeddah, KSA \\ Email: malajmi@kacst.edu.sa
}

How to cite this paper: Alajmi, M., Alotaibi, A., Aboud, E., Alharbi, A. and Almalki, M. (2018) Observations "Detections" of Shallow Unconventional Qusaiba Shale Gas Reservoirs North Part of Saudi Arabia. Journal of Geoscience and Environment Protection, 6, 257-265.

https://doi.org/10.4236/gep.2018.65022

Received: May 8, 2018

Accepted: May 28, 2018

Published: May 31, 2018

\begin{abstract}
There are many oil and gas conventional reservoirs in Saudi Arabia have been exploited, but still there are also need to be explored and produced especially in the fields of unconventional shale gas. Investigation the extending of rock source of the hot shale gas Qusaiba formation in North part of Saudi Arabia, the most important rock source in the word, is crucial for one of the most promising shallow shale gas reservoir in the region. Most previous studies in the area were a geological, petrographical, petrophysical, geochemical characteristics or well logs studies which are not enough to show the continuously of the reservoir and map the diverse of the depth changes. The lack of the geophysical studies in the area inspiring to perform such study and image how the continuously and behavior of the reservoir subsurface. Imaging the geological stratigraphy of area utilizing a multiple geophysical methods is a crucial step to disclosure the unconventional reservoir and understand the source rock extending underneath the North region of Saudi Arabia. A good achievement is shown in this study using this integration of seismic migrated image and gravity geological model. This integration provides a robust and true subsurface geological formations, structures, and determined thickness and depth of the Lower Silurian Sharawra Qusaiba and Sarah formations. This work would be a valuable contribution in unconventional reservoirs exploration in shale gas in Saudi Arabia.
\end{abstract}

\section{Keywords}

Unconventional Shale Gas, Qusaiba Formation, Seismic, Gravity, Saudi Arabia

\section{Introduction}

Shale gas plays a main role in the recent hydrocarbons exploration industry. 
North part of Saudi Arabia is one of the most promising unconventional gas reserves in shale gas reservoir geologically and known by Qusaiba Formation. The Qalibah Group is located in this part of the Arabian shield and consists of two Formations: the (upper) Silurian Sharawra Formation and the (lower) Qusaiba shale Formation. Silurian Sharawra consists mainly of sandstone and siltstone with beds of shale. The important of Silurian Sharawra is that it is laying over one the biggest rock source of hydrocarbon in the region Qusaiba Formation. The Formation is presented from outcrop exposures in subsurface in this part of Saudi Arabia [1]. The second Formation of Surilian Qalibah Paleozoic is Qusaiba Formation; it is classified as an organic-rick shale. The Formation mostly consists of shale and claystone embedded with small amount of siltstone and sandstone [2]. They reported the Qusaiba Formation occurrence in two sub-basins in Central and Eastern of Saudi Arabia. Moreover, the Qusaiba Formation is eroded recording to most recent reports in the area between the Central Arch Block anticline oil and gas North Gawar field, and North horst graben oil and gas of Saudi Arabia [3]. The expectation of oil and gas existences in Qusaiba could reach 37 billion barrels and 808 trillion cubic feet, respectively [3].

To explore the unconventional shale gas many studies and field works were conducted in several locations in Saudi Aribia. One of the interesting studies on unconventional shale gas was done in North West of Saudi Arabia to investigate pore pressure prediction for the hot shale of the Qusaiba formation and Sarah Formation using multi well logs data in the area supported with 3D seismic data [4]. They found the thickness of Qusaiba is diverse across the basin and that hot shale presents partially as seal formation for Sarah formation. The study was focused on the characterization of well logs and the pore pressure changes of $\mathrm{Qu}$ saiba hot shale without mentioned to the true depth and thickness of the formation. Jones and Stump [2] indicated that the thick part of Qusaiba formation is located South of Ar Riyad in the Southern basin. In contrast, at the North of Saudi Arabia, the Qusaiba Formation becomes thinner between $150 \mathrm{~m}$ to $300 \mathrm{~m}$ at the study area [5]. At the base of Qusaiba shale formation, there is a presence of black "hot shales" that is rich in organic matter. It is considered as a proven source rock of the Paleozoic hydrocarbons ranges in thickness between $30-70 \mathrm{~m}$ [2] [5]-[12].

Here, we aim to utilize the integration of high resolution reflection seismic and gravity data to image the sequence of subsurface layers and structures of near surface shale gas formations and verify of the reservoir characterization depth and thickness for unconventional gas fields exploration and production in the region.

In Tayma area in Saudi North part, determining the rock source Qusaiba Formation and detecting the top depth of the Formation will be most beneficial to verify the depth of hot shale gas and mitigate the uncertainties of source rock Surillian Qusaiba and Sarah Formation Figure 1. Furthermore, to study the differences in depths and dipping of the reservoir in the North part of Arabian Peninsula comparing with amount of study what have done on the basin in Central 


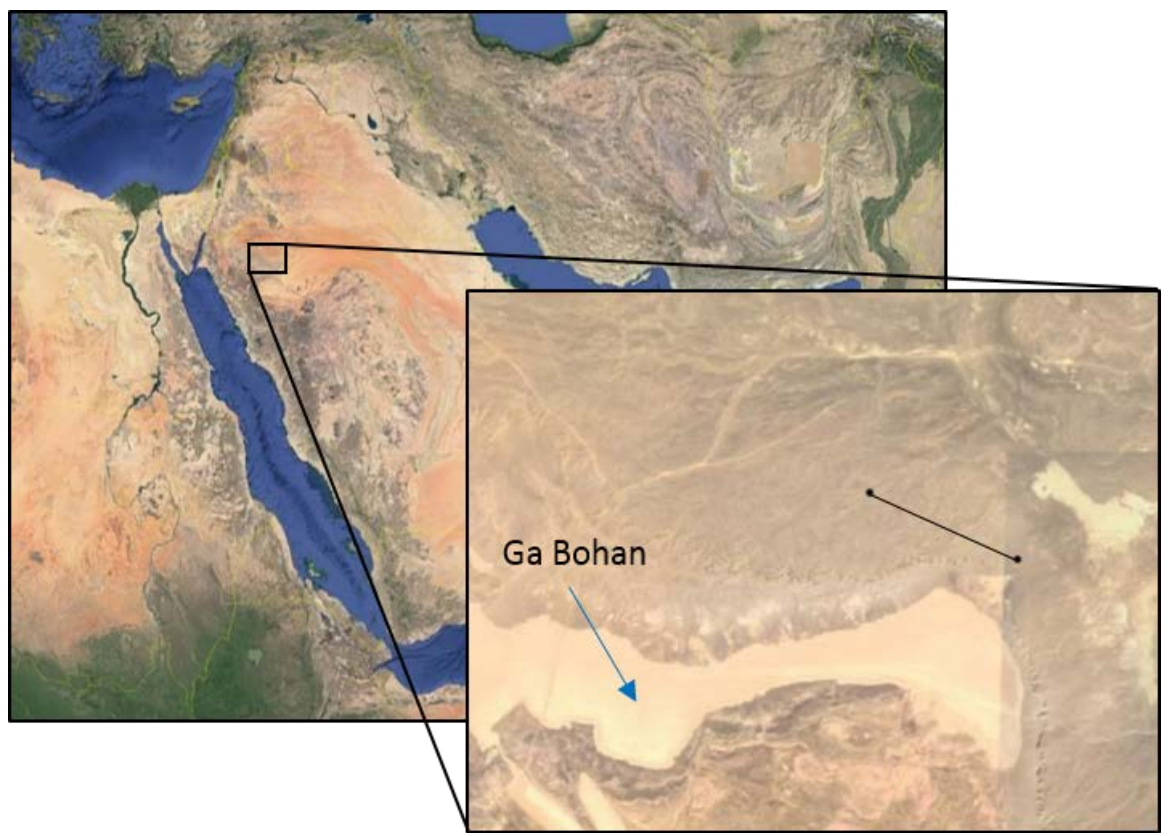

Figure 1. Map showing the location of study area at North part of Saudi Arabia. The black line in enlarge map indicates the seismic survey location which is identical to the gravity survey as well. In zoomed map, Ga Bohan is showed below the survey line which has a very hard surface.

and South Arch host of oil and gas.

\section{Method and Fieldwork}

Using the seismic imaging was so critical because the Qusaiba shale in North West is very shallow comparing to its depths in Central and South part. In this study, 2D seismic profile was acquired using 96 channel and 408 shots. The intervals of sources and receivers were $10 \mathrm{~m}$ with the minimum and maximum offsets $5 \mathrm{~m}$ and $950 \mathrm{~m}$, respectively. We utilize one Mini IVI Vibrosies source to shot 408 linear upsweep with bandwidth between $20-200 \mathrm{~Hz}$ and stacking 3 numbers of sweeps. The field Parameters were selected based on testing shots that showed the best parameters for the nature geological phenomena and area accessibility. The layout of seismic survey in study area was spreading on the top of Sharawra shale layer. It was suggested to have the seismic survey on the surrefce of Qa Buhan, but the idea changes because of some field observations Figure 2. Figure 2(A) shows the direction of the survey line which is placed on the hill instead what suggested on the surface Figure 2(C). The reason to change the location of survey line refers to hardness of Qa Buhan surface which makes spreading spike geophones into ground more difficult. In addition, Gravity data was acquired along the seismic line with $4100 \mathrm{~m}$ length and interval $100 \mathrm{~m}$ between stations to detect and map an unexplored lower Silrurian Qusaiba-Plaeozoic Formation. We mainly used gravity method to measure the distribution of density of the subsurface, mapping geologic model based on external constraints, and adding more understanding of the geological subsurface 

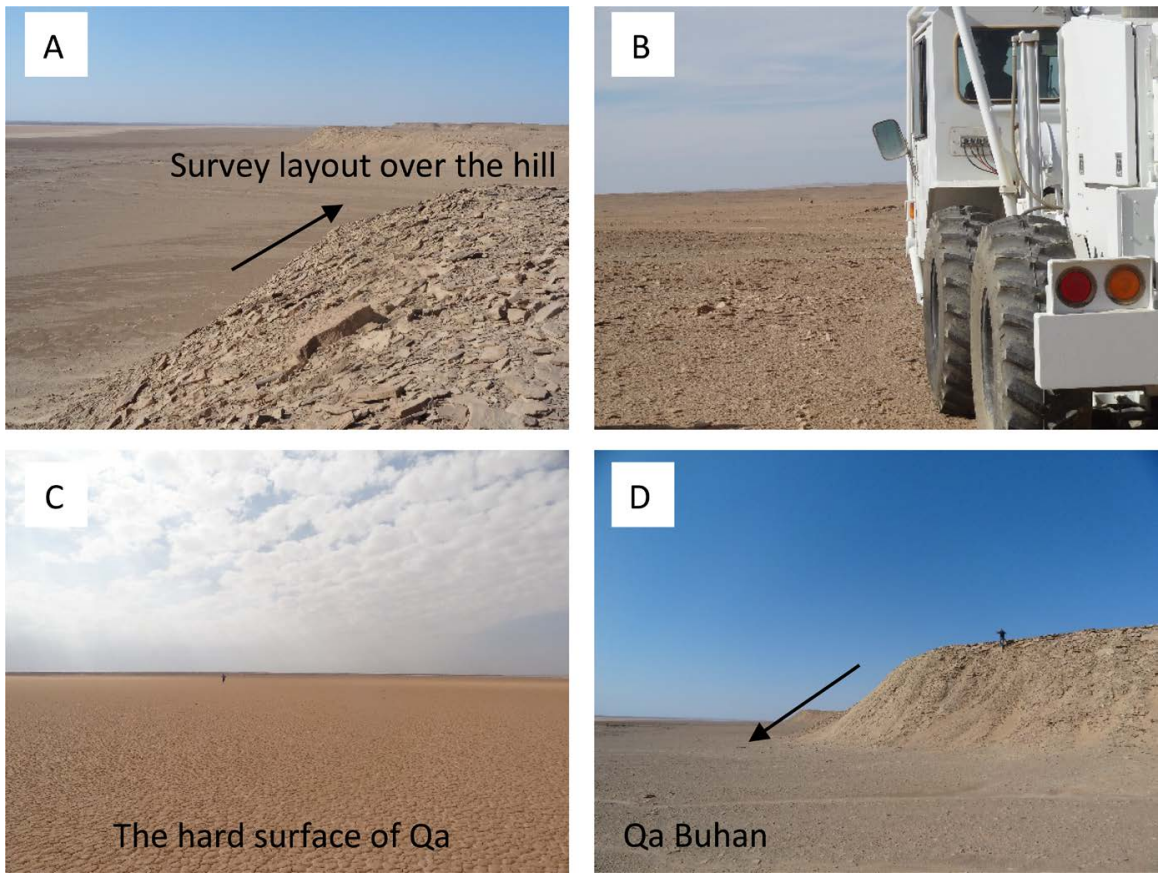

Figure 2. Shows the environment of the field observations. In photo (A), it can be clear the high of the hill which represents an outcrop of the Sharawra formation. The arrow in photo (B)refers to the direction of the survey location. Photo (D) shows the elevation of the hill and the arrow refers to other side of the area which is called Qa Buhan. Photo (C) shows the hard surface of the study area which makes the spreading of the seismic survey layout is an impossible especially with spike geophones.

structures. In the gravity interval, recording locations were identical with the seismic survey and exactly over the locations of the seismic source shots.

\section{Results and Discussions}

Commonly, Shale is heterogeneous and brittleness undersurface. The surface Sharawra formation is mainly composed of sandstone with many beds siltstone and shale. The strength of our source (Mini IVI Vibrosies source) is prop for near surface application but according to the lithology of the subsurface, we recognized absence of some high frequencies underneath and appear a wide of the ringing waves. These ringing and discontinuous horizons may refer to the lithology diversity between litstone and sandstone beds and brittleness shales layers inside Sharawra Formation in shallow part, which are marked by the red square in seismic section Figure 3. Sparitosh and D, Thomas [13] found that a strong seismic expression and multiples ringing in the continuously of the P-wave gathers were existed in the shallow reservoir of sandstone surrounding by shale beds causes. That may be caused by the differences in the acoustic impedance between sandstone and shale that gives a weak contrast. Moreover, the stress and orientation of shale beds with lower and upper litstone and sandstone may cause more attenuation of high frequencies signals.

In Figure 3, seismic section also shows strong horizon events at depth 230 and at depths between $370-390 \mathrm{~m}$. The horizons denote the tops of the Qusaiba "hot 


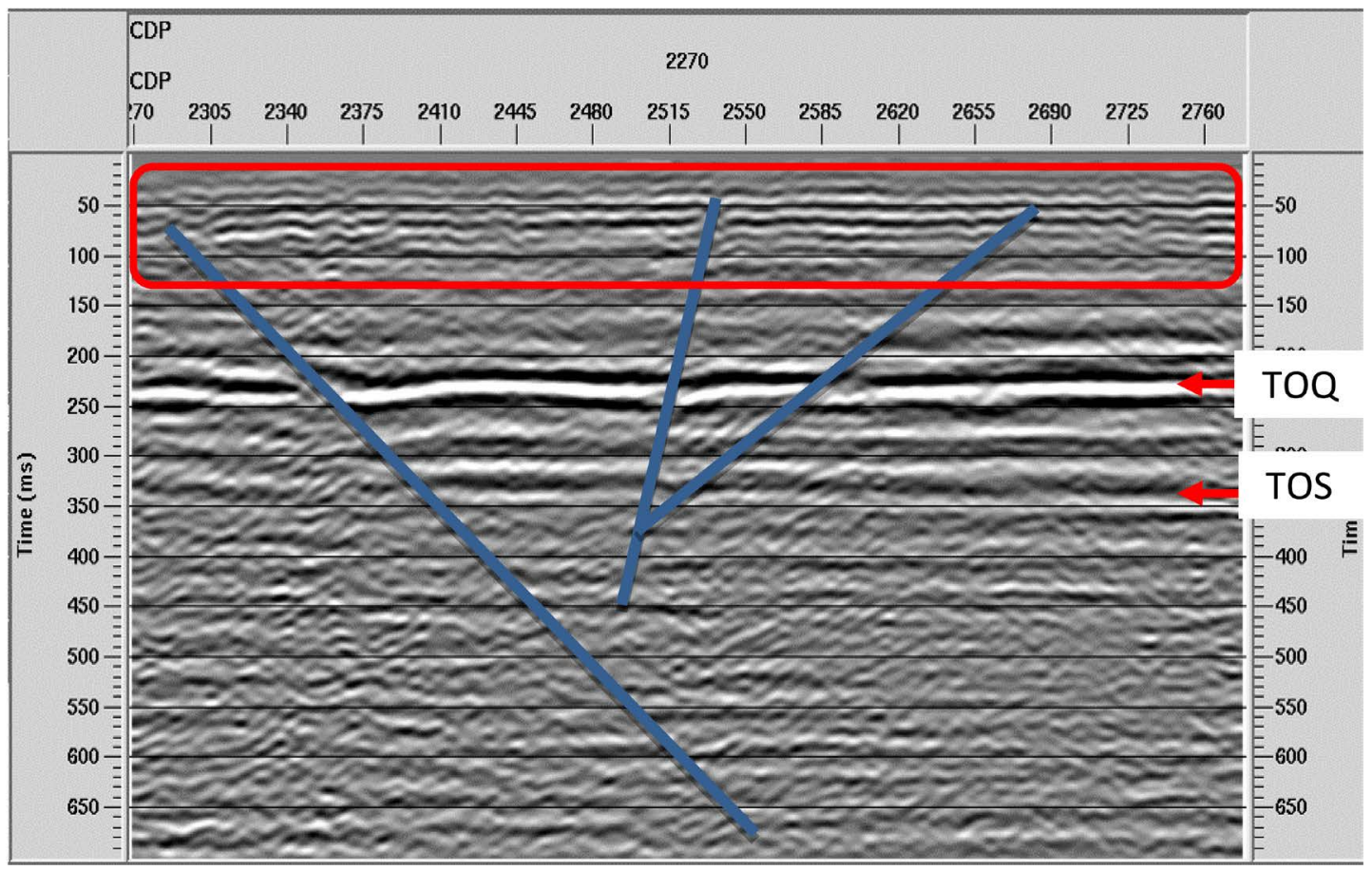

Figure 3. Shows the prestack time migration of the area with gather intervals $10 \mathrm{~m}$ and maximum offsets 950 $\mathrm{m}$, for 409 shots. The red square indicates some shallow shale beds and demonstrates the evidences of the Sharawra shale formation on the surface. Also in the section the detection of the top of Qusaiba formations (TOQF) is imaged on the $230 \mathrm{~m}$ with thickness between $70-90 \mathrm{~m}$ along the profile, and followed by the top of the Sarah formation (TOSF) at 300 to 320 . Moreover, the interpretation of the section shows some shallow faults, which are marked by blue lines.

shale" (TOQF) and Sarah formation (TOSF) with some interactions of shallow geological structures and faults appearing in the middle of the section. According to high frequencies signals attenuation caused by sandstone surrounding Sharawra shale beds with lower and upper huge amplitude energy were loose and caused absent of the deep formation beneath the Sarah formation.

Figure 4 shows the diversity of both sandstone and shale interbeds along the outcrop in the area which is continued throughout subsurface Sharawra formation and that gives an evidence of the appearance of the near surface ringing waves in seismic section.

Gravity data was acquired along the seismic line with $4100 \mathrm{~m}$ length and interval $100 \mathrm{~m}$ between stations to detect and map an unexplored lower Silrurian Qusaiba-Plaeozoic Formation. Figure 5(A) shows the processed gravity data utilizing GM-SYS Profile modelling platform. The accurate processing and modeling results usually help to achieve more accurate and detailed subsurface novel and decrease the uncertainties in the interpretation modeling. The geological modelling observed from the gravity data shows brilliant mapping of TOQF and TOSF with roughly same detections of the depth and dipping in seismic imaged result. The both modeling gives the same depth of TOQF along the profile at depth roughly $230 \mathrm{~m}$ with change in range of $40-60 \mathrm{~m}$. Note, the seismic result, here, was cropped in both sides to remove the affection of the migration imaging. 


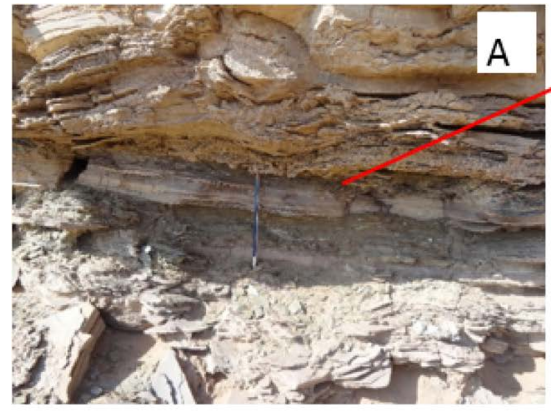

\section{Enlarge of the sandstone and shale interbeds from}

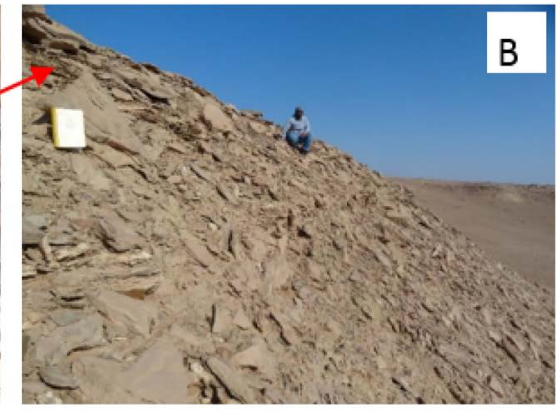

Sharawra formation

outcrop

Figure 4. (A) Shows the interbeds shale and sandstone beds of Sharawra formation and (B) Shows the outcrop of the formation.
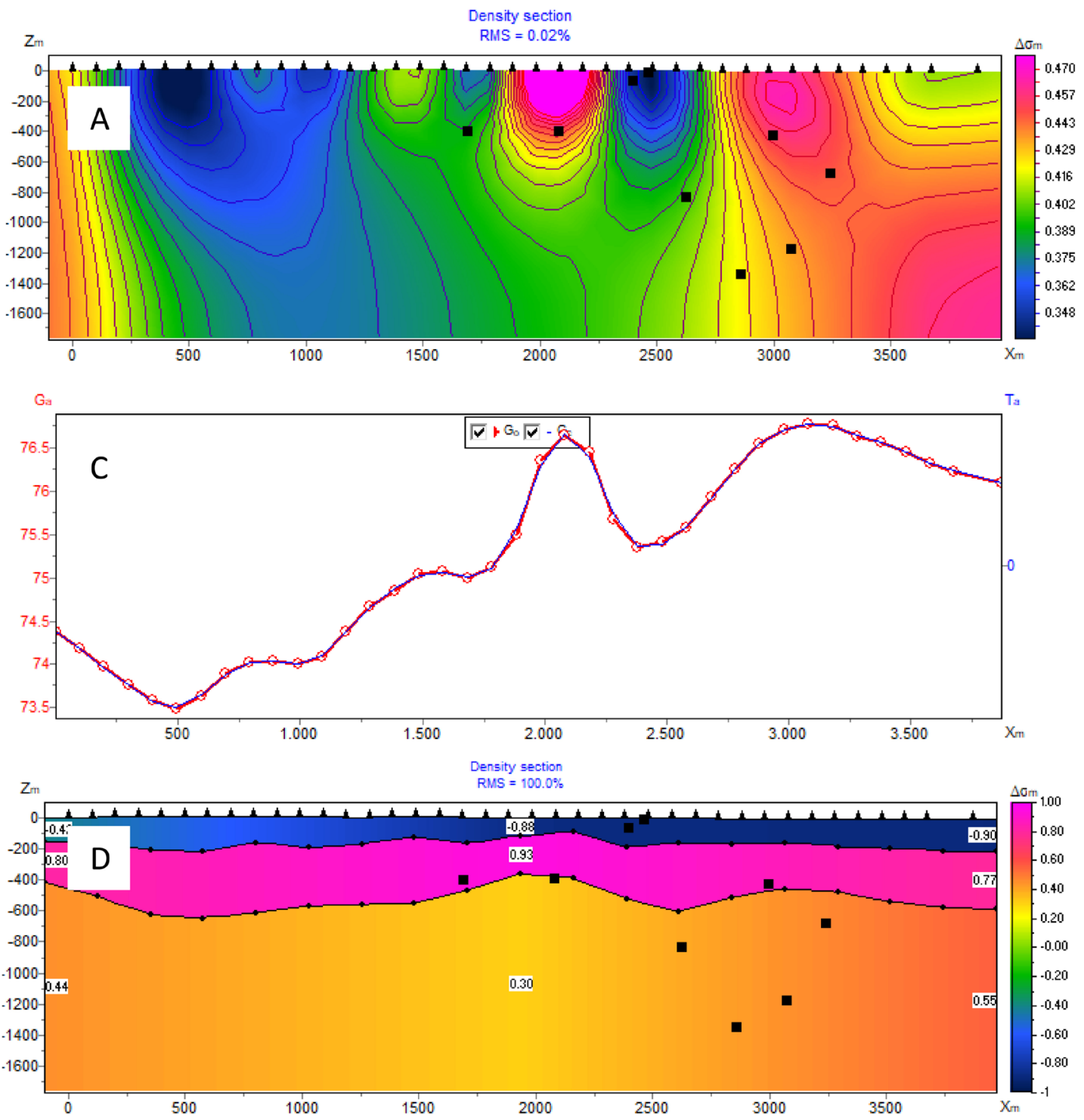

Figure 5. Shows the gravity processing profile and interpretation modeling result of the gravity survey of the area. The gravity survey is identical with the seismic along and recorded on the locations of the seismic source shots. (A) Shows a result of gridding 2D profile with some high anomalies in the end of the survey area. (B) GM-SYS Profile Modelling was utilized to map an accurate geological model by picking observed measurements of diverse subsurface gravity recording (D). 
Therefore, the gravity geological model seems longer the seismic data Figure 6.

\section{Conclusion}

Mapping the subsurface of organic-rich shale gas of the Lower Silurian Qusaiba formation and Sarah formation are performed using the integration of seismic and gravity data. The investigation of the unconventional Qusaiba hot shale reservoir in North of Saudi Arabia is necessary to increase the possibilities of exploring the shale gas field in the area and to decrease the uncertainties of subsurface depth and thickness of the rock source. Imaging of the migrated $2 \mathrm{D}$ seismic data and modeling of $2 \mathrm{D}$ profile gravity data are performed in order to distinguish the subsurface formations and detect their depths and thicknesses. The present integration modeling and imaging results are showing identical

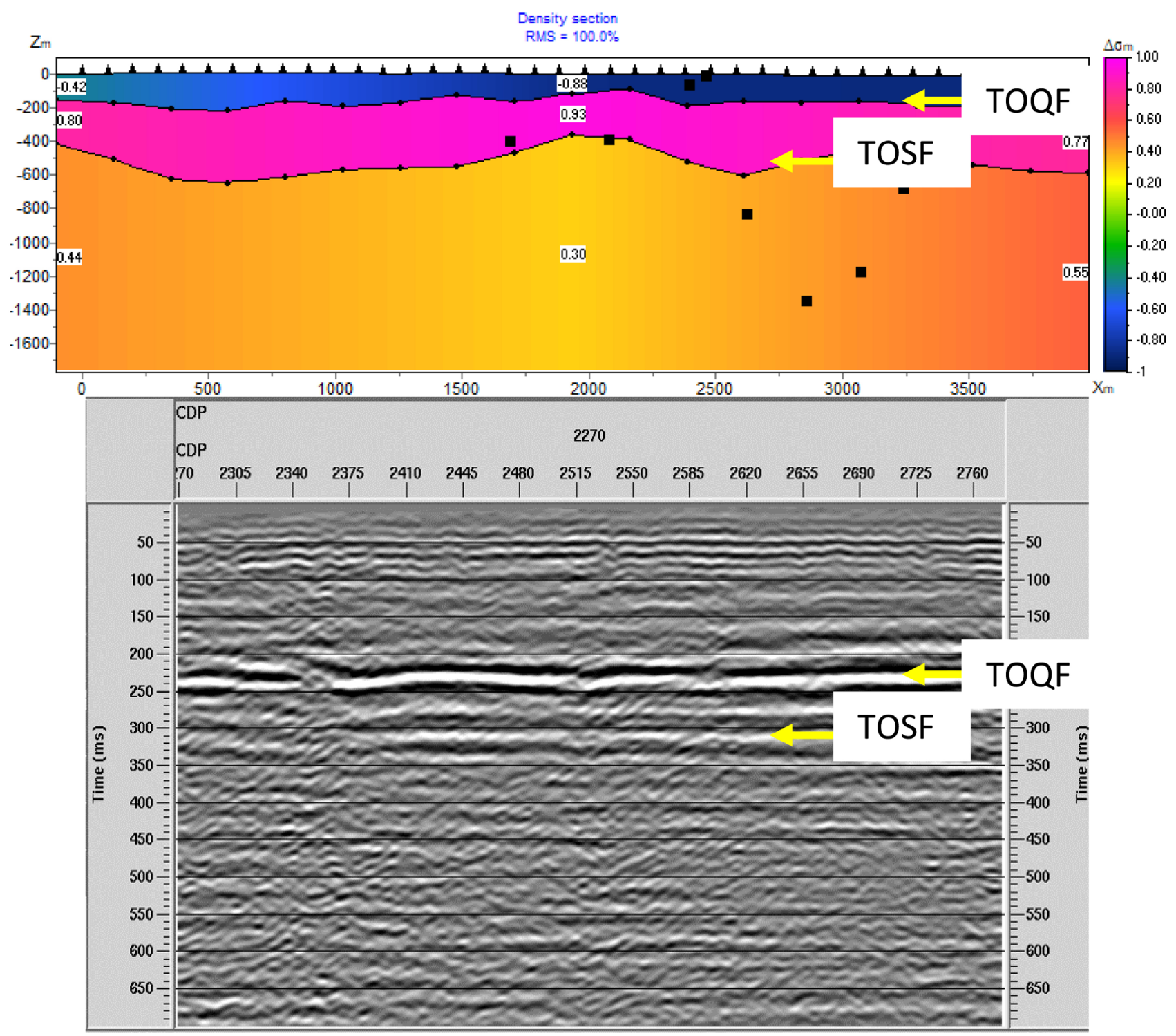

Figure 6. Shows results of the area of the geological gravity model (A) and the seismic image (B). The comparison between models shows a robust detection for both formations TOQF and TOSF. The depth scale and the length of the two models are different. 
detections of three formations: Sharawra (on surface) followed by Qusaiba and Sarah formations. The depth of the shale gas Qusaiba formation is diverse and the continuously is interpret with some shallow geological faults. The result of migrated seismic prove the laying of Sharawra formation on the surface which is ascertained as well by the field surface scenes and evidences of the outcrop. The lithology of the Sharawra formation exhibition with a series of sandstone interfering with thin interbed shale along the Formation cause a wide of multiple ringing in shallow seismic waves. The work result adds a respected contribution in shale gas unconventional reservoir exploration and development in North part of the Saudi Arabia, but it needs more data for verification and covered field works to discover the area significantly. Moreover, it is highly important to increase the income profits for Saudi Arabia in shale gas.

\section{Acknowledgements}

The author would like to acknowledge King Abdulaziz City for Science and Technology for supporting this work. Many thanks shall extend the geophysical team of KACST for conducting some activities related to this study.

\section{References}

[1] Al-Laboun, A.A. (2009) Tectonostratigraphy of the Exposed Silurian Deposits in Arabia. Arabian Journal of Geosciences, 2, 119-131. https://doi.org/10.1007/s12517-008-0017-x

[2] Jones, P.J. and Stump, T.E. (1999) Depositional and Tectonic Setting of the Lower Silurian Hydrocarbon Source Rock Facies, Central Saudi Arabia. AAPG Bulletin, 83, 314-332.

[3] Geological Survey (U.S.) (2002) Undiscovered Oil and Gas Resources of Lower Silurian Qusaiba-Paleozoic Total Petroleum Systems, Arabian Peninsula. U.S. Dept. of the Interior, U.S. Geological Survey, Reston, Va.

[4] Mujica, D. and Aldajani, A. (2013) Pore Pressure Prediction from 3D Seismic Data: A Feasibility Study for Unconventional Gas in Saudi Arabia. SEG Technical Program Expanded Abstracts 2013, 2331-2335. https://doi.org/10.1190/segam2013-0265.1

[5] Mahmoud, M.D., Vaslet, D. and Husseini, M.I. (1992) The Lower Silurian Qalibah Formation of Saudi Arabia: An Important Hydrocarbon Source Rock. AAPG Bull., 76, $1491 \mathrm{e} 1506$.

[6] Abu-Ali, M.A., Franz, U.A., Shen, J., Monnier, F., Mahmoud, M.D. and Chambers, T.M. (1991) Hydrocarbon Generation and Migration in the Paleozoic Sequence of Saudi Arabia. Society of Petroleum Engineers, SPE 21376, 345-356.

[7] Abu-Ali, M.A., Rudkiewicz, J.L.L., McGillivray, J.G. and Behar, F. (1999) Paleozoic Petroleum System of Central Saudi Arabia. GeoArabia, 4, 321 e336.

[8] McGillivary, J.G. and Husseini, M.I. (1992) The Paleozoic Petroleum Geology of Central Arabia. AAPG Bull., 76, 1473e1490.

[9] Cole, G.A., Abu-Ali, M.A., Aoudeh, S.M., Carrigan, W.J., Chen, H.H., Colling, E.L., Gwathney, W.J., Al-Hajri, A.A., Halpern, H.I., Jones, P.J., Al-Sharidi, S.H. and Tobey, M.H. (1994) Organic Geochemistry of the Paleozoic Petroleum System of Saudi Arabia. Energy Fuels, 8, 1425e1442. 
[10] Wender, L.E., Bryant, J.W., Dickens, M.F., Neville, A.S. and Al-Moqbel, A.M. (1998) Paleozoic (Pre-Khuff) Hydrocarbon Geology of the Ghawar Area, Eastern Saudi Arabia. GeoArabia, 3, 273-302.

[11] Konert, G., Afifi, A.M., Al-Hajri, S.A. and Droste, H.J. (2001) Paleozoic Stratigraphy and Hydrocarbon Habitat of the Arabian Plate. GeoArabia, 6, 407-442.

[12] Abu-Ali, M.A. and Littke, R. (2005) Paleozoic Petroleum Systems of Saudi Arabia: A Basin Modeling Approach. GeoArabia, 10, 131-168.

[13] Singh, P. and Davis, T. (2011) Advantages of Shear Wave Seismic in Morrow Sandstone Detection. International Journal of Geophysics. 